\title{
Thinning and Flow of Tibetan Crust Constrained by Seismic Anisotropy
}

\author{
Nikolai M. Shapiro, ${ }^{1 *}$ Michael H. Ritzwoller, ${ }^{1}$ Peter Molnar, ${ }^{2}$ \\ Vadim Levin ${ }^{3}$
}

\begin{abstract}
Intermediate-period Rayleigh and Love waves propagating across Tibet indicate marked radial anisotropy within the middle-to-lower crust, consistent with a thinning of the middle crust by about $30 \%$. The anisotropy is largest in the western part of the plateau, where moment tensors of earthquakes indicate active crustal thinning. The preferred orientation of mica crystals resulting from the crustal thinning can account for the observed anisotropy. The middle-to-lower crust of Tibet appears to have thinned more than the upper crust, consistent with deformation of a mechanically weak layer that flows as if confined to a channel.
\end{abstract}

Although most of the high terrain and the thick crust of the Tibetan plateau has resulted from India's generally northward penetration into Eurasia, east-west extension and crustal thinning dominate the current active deformation in the highest parts of the plateau $(1-3)$. Both of the principal processes that are believed to cause this change in the style of deformation involve crustal flow. The first is that dense mantle material may have been removed from beneath Tibet, causing its plateau's surface to rise and its entire lithosphere to extend horizontally and to thin (4). The second involves a warming and weakening of the middle and lower crust (5), which favors lateral crustal flow (6-8). These processes are not necessarily independent, because the weakening of the Tibetan crust by conductive warming would require tens of millions of years unless other processes such as the removal of mantle material (9) or frictional heating (10) were involved. Thus, the details of the current deformation within the crust and uppermost mantle beneath Tibet remain poorly understood. There are, however, two prominent hypotheses about the vertical distribution of crustal flow: First, both the crust and the mantle lithosphere beneath Tibet deform essentially coherently as a thin viscous sheet (11-13), and, second, crustal thinning is dominated by flow in a channel within the mid-to-lower crust (5-8).

The dispersion (or dependence of wave speed on period) of Love and Rayleigh waves, which are horizontally and vertically polarized, respectively, requires radial anisotropy within the middle and lower crust. On

${ }^{1}$ Center for Imaging the Earth's Interior, Department of Physics, ${ }^{2}$ Department of Geological Sciences, Cooperative Institute for Research in Environmental Science (CIRES), University of Colorado at Boulder, Boulder, CO 80309, USA. ${ }^{3}$ Department of Geological Sciences, Rutgers University, Piscataway, NJ 08854, USA.

*To whom correspondence should be addressed. Email: nshapiro@ciei.colorado.edu individual seismic records (Fig. 1) and the resulting dispersion maps (Fig. 2A), we observed that the group speed of Rayleigh waves crossing Tibet decreases between 10-s and 35-s periods and then increases again at longer periods, whereas the dispersion of Love waves at these periods remains near normal and increases approximately monotonically with period. Simple models of isotropic seismic wave speeds in the crust cannot fit simultaneously the Rayleigh and Love wave group-speed dispersion curves observed across Tibet (Fig. 2, A and B). The difference between the surface wave speeds from the best-fitting isotropic model and the observations (Fig. 2A) is much larger than the data errors (14). The dispersion curves
A
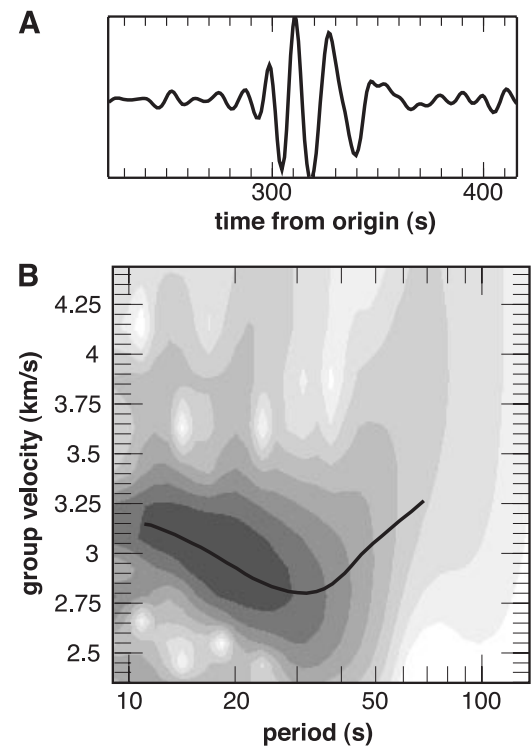

require a radially anisotropic crust (transverse isotropy with a vertical symmetry axis) with a horizontally polarized shear wave $\left(S_{\mathrm{h}}\right)$ speed $\left(V_{S_{\mathrm{h}}}\right)$ greater than the shear wave speed for a vertically polarized $S_{\mathrm{v}}$ wave $\left(V_{S_{\mathrm{v}}}\right)$. (Radial anisotropy should be contrasted with azimuthal anisotropy, in which the fast axis of propagation lies in the horizontal plane and wave speeds are azimuthally dependent.) The radial anisotropy in the Tibetan crust is reminiscent of similar anisotropy in the mantle that manifests as a much longer period Rayleigh-Love discrepancy (15) but must have different causes, because the mineralogy of the crust and mantle differ from one another.

To study the spatial extent and strength of the radial anisotropy in the Tibetan crust, we combined surface wave dispersion measurements from more than 45,000 crossing paths (16) (fig. S1) with published phase speed measurements $(15,17)$ to constrain the threedimensional (3D) distribution of shear wave speeds in the Tibetan crust and uppermost mantle. To improve lateral resolution, we added more than 2500 group-speed dispersion measurements from portable broadband seismic stations installed within and in the vicinity of Tibet (18).

We followed a two-step inversion procedure. First, we used surface-wave diffraction tomography (14) to construct dispersion maps at periods ranging from $18 \mathrm{~s}$ to $200 \mathrm{~s}$ for group speeds and from $40 \mathrm{~s}$ to $150 \mathrm{~s}$ for phase speeds. This was followed by a Monte Carlo method (19) to invert the regionalized dispersion curves for the shear wave speed of the

C
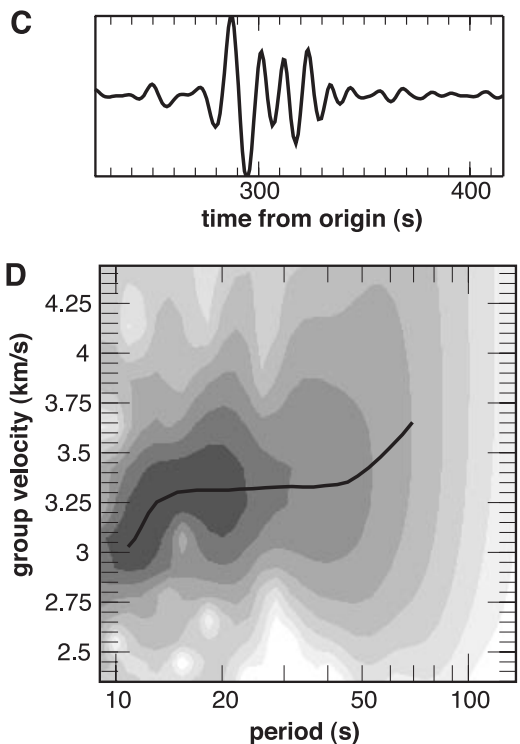

Fig. 1. Dispersion of intermediate-period Rayleigh and Love waves for a path across Tibet. (A) Vertical-component (Rayleigh wave) seismogram bandpassed between 15 and $100 \mathrm{~s}$. (B) The frequency-time diagram for the record in (A) showing the anomalous Rayleigh wave dispersion. (C) Transverse-component (Love wave) seismogram bandpassed between 15 and 100 s. (D) Transverse-component frequency-time diagram showing normal Love wave dispersion. Black lines on (B) and (D) are the measured group-speed curves for this path (shown in Fig. 3) between an earthquake on 28 March 1999 and a seismic receiver from the INDEPTH-3 experiment. 


\section{RE P O R T S}

crust and the uppermost mantle on a $1^{\circ}$-by- $1^{\circ}$ grid. Results of the inversion show that the observed dispersion curves require the presence of strong radial anisotropy in the middle Tibetan crust (Fig. 2, C and D and table S1). Previous surface-wave studies in Tibet ( 9 , 20-23) have not detected this crustal anisotropy because of either a shortage of data or exclusive reliance on Rayleigh waves. Analyses of teleseismic receiver functions (24, 25 ) also require an anisotropic crust.

The mid-crustal radial anisotropy stands out most clearly beneath the high plateau between $80^{\circ} \mathrm{E}$ and $95^{\circ} \mathrm{E}$ (Fig. 2E). Because of the limited vertical resolution of surface waves, we cannot constrain tightly the depth extent or magnitude of the radial anisotropy, and we prefer to represent its vertically averaged strength by the idealized travel time difference between $S_{\mathrm{v}}$ and $S_{\mathrm{h}}$ waves that are imagined to propagate vertically through the middle crust. Similarly, because of the limited horizontal resolution of the 3D model, we do not interpret the details of the spatial distribution but concentrate on robust features of the ensemble of acceptable structures, which we estimated from the Monte Carlo inversion (19). For each geographical location, in addition to the best-fitting structure, we determine the structure with the minimal crustal anisotropy that fits the dispersion curves within their uncertainties (Fig. 2F). In some areas outside of the high plateau, although the best-fitting structure contains notable anisotropy, the data can be explained almost as well with a nearly isotropic crust. Only beneath the high plateau do the observed dispersion curves require strong crustal radial anisotropy. Therefore, we interpret the midcrustal anisotropy only from this part of Tibet, for which we estimate the average $t_{S_{v}}-t_{S_{\mathrm{b}}}$ travel time difference to be $0.5 \pm 0.18 \mathrm{~s}$.

It has been suggested that, because of its strongly anisotropic behavior, mica may play the most important role in the formation of mid-to-lower crustal anisotropy (26-28), with the shear moduli polarized parallel to the plane of mica crystals being larger than those polarized perpendicular to the crystals (29). Thus, a near-horizontal orientation of mica crystals immersed in a matrix of isotropic crystals can produce radial anisotropy. (This distribution of mica crystals will not produce azimuthal anisotropy.)

Two different deformation mechanisms of the middle Tibetan crust could result in a preferred horizontal orientation of mica. First, strong shearing during the underthrusting of the Indian crust beneath Tibet (30) might realign these crystals. Second, the mica crystals can become oriented near-horizontally as a result of ongoing crustal thinning. (Horizontal shortening of the Tibetan crust by pure shear would result in a preferred vertical orientation of mica crystals and anisotropy opposite from what we observed.) The observed lateral distribution of the radial crustal anisotropy can help to discriminate between these mechanisms. If the thick Tibetan crust were created by large-scale underthrusting that caused radial anisotropy, we would expect strong radial anisotropy to be observed over the whole plateau wherever the crust is thick. In the second case, however, if the anisotropy resulted from crustal thinning, it would be most pronounced where the thinning has occurred.

Slips on faults during earthquakes provide information about current deformation within Tibet. The relatively low strain rate in Tibet $\left(\sim 10^{-8}\right.$ per year) $(31)$ and the short duration for which earthquakes can be studied prevent the observed seismicity from providing more than an approximate representation of crustal strain. Therefore, we use a simple approach
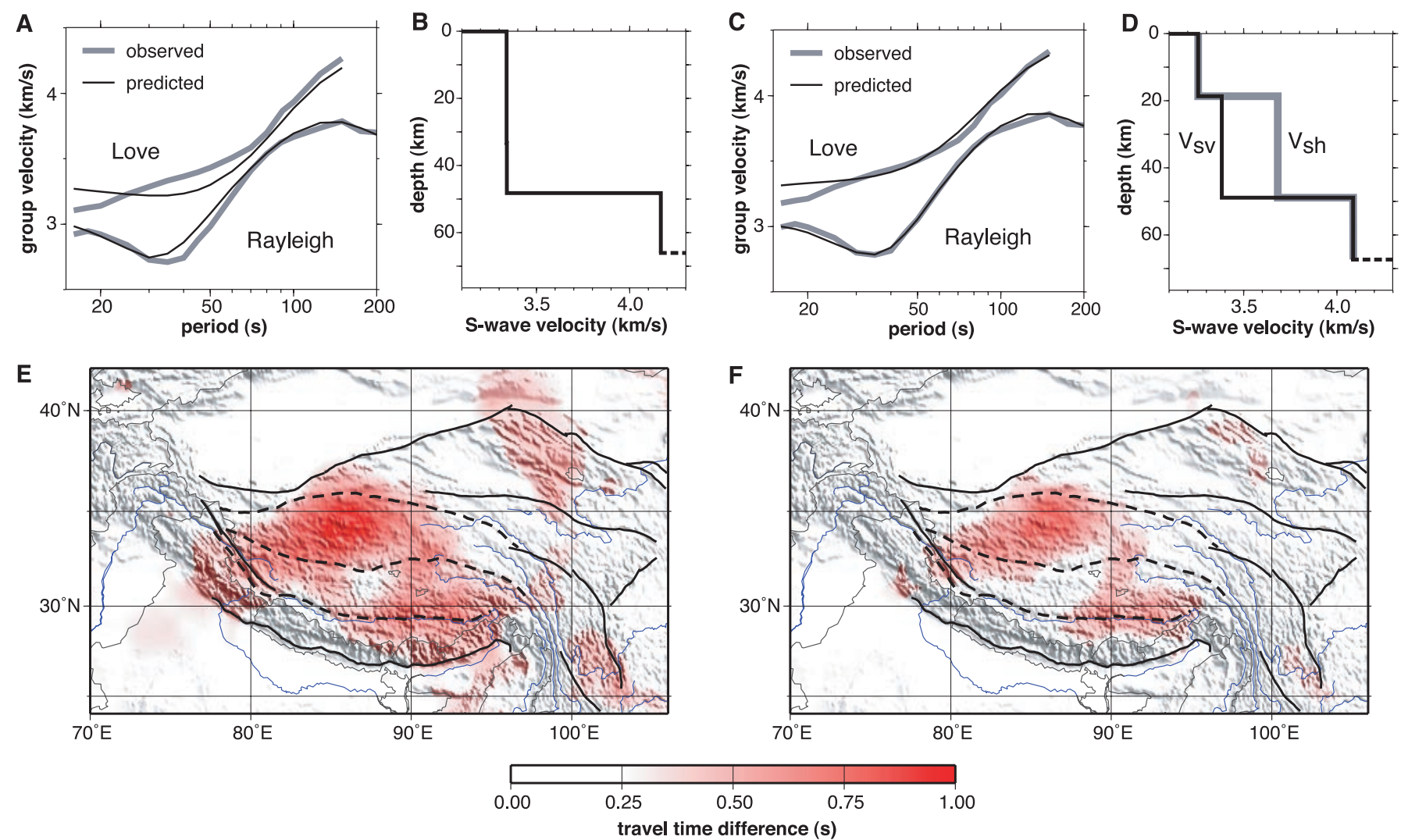

Fig. 2. Radial anisotropy in the Tibetan crust. [(A) to (D)] Surface-wave dispersion inversion for a point in western Tibet $\left(34^{\circ} \mathrm{N}, 84^{\circ} \mathrm{N}\right)$. (A) Fit to the observed dispersion curves with the monotonically increasing, isotropic parameterization of the shear wave speeds in the crust seen in (B). (C) Fit with radial anisotropy in the middle crust seen in (D). In (A) and (C), the predicted (thin black line) group speed dispersion curves correspond to the best-fitting crustal structures in (B) and (D), respectively. (E)
Strength of radial anisotropy in the middle crust from the best-fitting radially anisotropic model, represented as the idealized travel time difference between $S_{\mathrm{v}}$ and $S_{\mathrm{h}}$ waves propagating vertically through the middle crust. (F) The minimum strength of radial anisotropy required to explain the surface-wave dispersion data, presented as in (E). Solid lines in $(E)$ and $(F)$ show selected major active faults, and dashed lines are approximate locations of sutures. 
to deduce the current deformation regime and exploit only the sign of one component of the moment tensor (32), $M_{\mathrm{rr}}$, which measures the extent to which the slip during an earthquake contributes to crustal thinning or thickening. The distribution of $M_{\mathrm{rr}}$ for earthquakes shallower than $40 \mathrm{~km}$ (Fig. 3 ) shows that the crust is actively thinning in the same regions where we found the mid-crustal radial anisotropy (Fig. 2, E and F). This correspondence suggests that it is crustal thinning and the resulting rotation of mica crystals into a preferred horizontal alignment that makes the mid-tolower crust of Tibet anisotropic.

To quantify the relation between crustal thinning and the resulting crustal anisotropy, we estimated the strength of the radial anisot- ropy in deformed rock aggregates containing $30 \%$ mica ( $15 \%$ biotite and $15 \%$ muscovite) embedded in an isotropic matrix (33). We considered the simplest case of radially symmetric flattening (Fig. 4A), for which the rotation of mica crystals results in a transversely isotropic system with a vertical axis of symmetry, i.e., radial anisotropy with $V_{S_{\mathrm{b}}}>V_{S_{\mathrm{v}}}$ as observed in Tibet. We used laboratory measurements of elastic constants of mica (29) and the Voigt-Reuss-Hill averaging scheme to estimate the elastic tensor and the shear wave speeds of the deformed aggregate as a function of the vertical thinning of the crust (Fig. 4B) (33). The difference between $S_{\mathrm{v}}$ and $S_{\mathrm{h}}$ vertical travel times (Fig. 4C) depends not only on the strength of

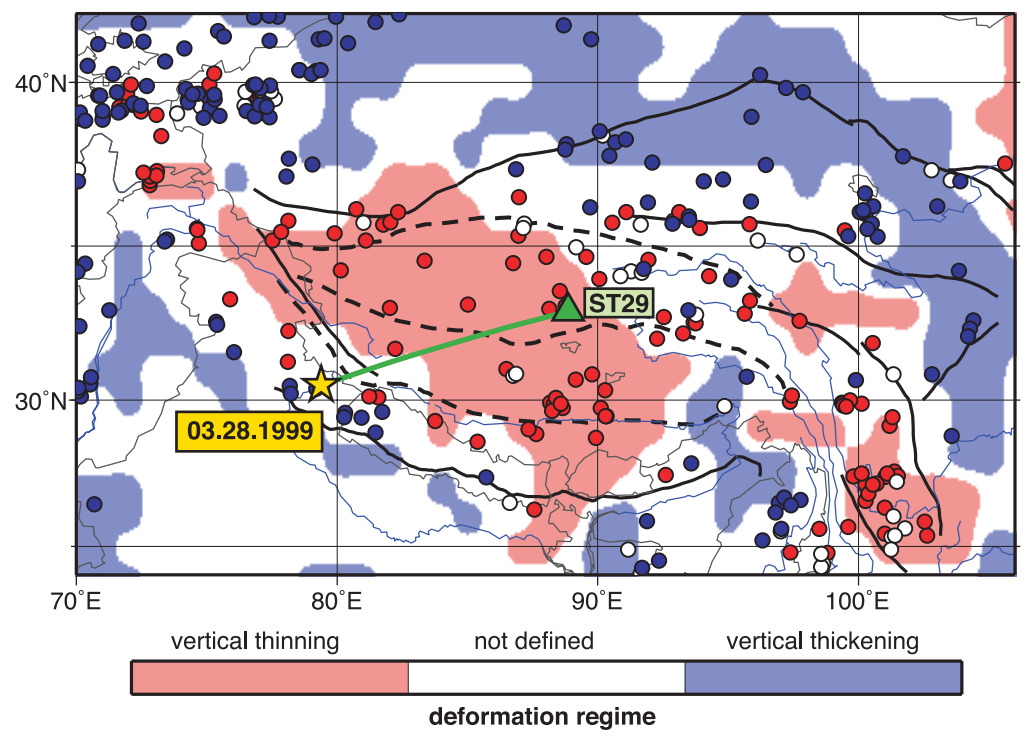

Fig. 3. Evidence for ongoing crustal thinning from earthquakes. The distribution of the normalized $\tilde{M}_{r r}$ component of seismic moment tensors across Tibet $\left[\tilde{M}_{r r}=M_{r r}\right.$ / $\left.\max \left(M_{r r r}, M_{\theta \theta}, M_{\phi \phi}^{r r}\right)\right]$. Earthquakes contributing to crustal thinning $\left(\tilde{M}_{r r} \leq-0.15\right)$ are shown with red circles, and those corresponding to crustal thickening $\left(\tilde{M}_{\mathrm{rr}} \geq 0.15\right)$ are shown with the blue circles. White circles denote earthquakes for which $\left|\tilde{M}_{\mathrm{rr}}\right|$ is small. Light red shading shows areas where earthquakes with $\tilde{M}_{\mathrm{rr}} \leq-0.15$ are detected within a $200-\mathrm{km}$ radius, and no earthquakes with $\tilde{M}_{\mathrm{rr}} \geq 0.15$ are detected in the same area. Light blue shading shows the same for $\tilde{M}_{\mathrm{rr}} \geq$ 0.15 and no events with $\tilde{M}_{r r} \leq-0.15$. The green line is the ray path for the seismic records shown in Fig. 1.
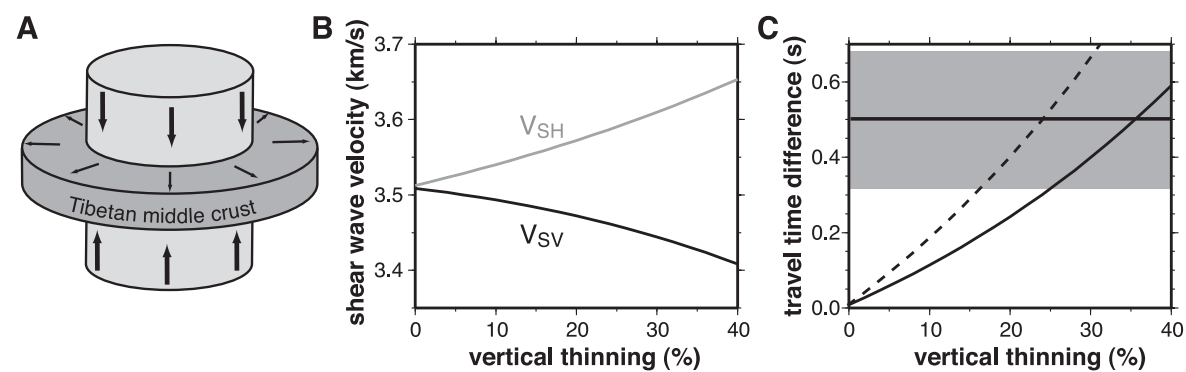

Fig. 4. Relationship between the observed mid-crustal radial anisotropy and the ongoing deformation of the Tibetan crust. (A) Radial flow envisioned for the Tibetan crust. (B) $V_{S_{y}}$ and $V_{S_{\text {b }}}$ computed for a mineralogical aggregate consisting of $15 \%$ biotite, $15 \%$ muscovite, and $70 \%$ isotropic matrix as a function of the flattening strain. (C) Travel time difference between $S_{v}$ and $S_{h}$ waves propagating through the deformed crustal layers with thicknesses of $30 \mathrm{~km}$ (solid line) and $50 \mathrm{~km}$ (dashed line). The horizontal line and the shaded area indicate the average travel time difference and its standard deviation estimated for western Tibet from surface wave dispersion $(0.5 \pm 0.18 \mathrm{~s})$.

anisotropy but also on the thickness of the anisotropic layer, which is constrained only somewhat by the surface-wave inversion. Our results indicate that radial anisotropy is required in the middle crust, but we cannot exclude the possibility that the anisotropic layer extends into the lower crust. If the anisotropic layer were limited to the middle crust, its thickness would be about 25 to 30 $\mathrm{km}$, but it might be as thick as $50 \mathrm{~km}$ if the lower crust were also included. From surface observations and the assumption of an average thinning strain rate of $10^{-8}$ per year acting for 10 million years, the Tibetan crust would have thinned, i.e., vertically flattened, by about $10 \%$ of its thickness. Depending on the assumed thickness of the anisotropic layer, however, we find that a vertical flattening strain of between $20 \%$ and $40 \%$ would be required to produce the observed radial anisotropy in a rock containing 30\% mica.

The flattening needed to explain the radial anisotropy of the mid-to-lower crust (20\% to $40 \%$ ) is, therefore, two to four times larger than the flattening manifest at the surface, implying that at least half of the thinning of the Tibetan crust has occurred in the mid-tolower crust. Other evidence suggests that the middle crust of Tibet, at least in some regions, is hot, if not partially molten, and hence very weak $(34,35)$. The observed radial anisotropy, therefore, supports the idea that much of the thinning of the crust that has followed the collision between India and Eurasia has been produced by channel flow within the mid-to-lower crust of Tibet (5-8).

\section{References and Notes}

1. P. Molnar, P. Tapponnier, J. Geophys. Res. 83, 5361 (1978).

2. R. Armijo, P. Tapponnier, J. L. Mercier, T. L. Han, J. Geophys. Res. 91, 13803 (1986).

3. P. Molnar, H. Lyon-Caen, Geophys. J. Int. 99, 123 (1989).

4. P. England, G. Houseman, J. Geophys. Res. 94, 17561 (1989).

5. P. Bird, J. Geophys. Res. 96, 10275 (1991).

6. L. H. Royden et al., Science 276, 788 (1997).

7. M. K. Clark, L. H. Royden, Geology 28, 703 (2000).

8. C. Beaumont, R. A. Jamieson, M. H. Nguyen, B. Lee, Nature 414, 738 (2001).

9. W.-P. Chen, P. Molnar, J. Geophys. Res. 86, 5937 (1981).

10. C. Kincaid, P. Silver, Earth Planet. Sci. Lett. 142, 271 (1996).

11. P. England, G. Houseman, J. Geophys. Res. 91, 3664 (1986).

12. P. England, P. Molnar, Science 278, 647 (1997).

13. L. M. Flesch, A. J. Haines, W. E. Holt, J. Geophys. Res. 106, 16435 (2001).

14. M. H. Ritzwoller, N. M. Shapiro, M. P. Barmin, A. L. Levshin, J. Geophys. Res. 107, 2335 (2002).

15. G. Ekström, A. M. Dziewonski, Nature 394, 168 (1998).

16. M. H. Ritzwoller, A. L. Levshin, J. Geophys. Res. 103, 4839 (1998).

17. J. Trampert, J. H. Woodhouse, Geophys. J. Int. 122, 675 (1995)

18. We used data from the Tibetan Plateau, INDEPTH-3, the Tien Shan (36), and Himalayan Nepal Tibet Experiment (HIMNT) (37) PASSCAL deployments.

19. N. M. Shapiro, M. H. Ritzwoller, Geophys. J. Int. 151, 88 (2002). 
20. N. Cotte et al., Geophys. J. Int. 138, 809 (1999).

21. W. Friederich, Geophys. J. Int. 153, 88 (2003).

22. Z. Huang, W. Su, Y. Peng, Y. Zheng, H. Li, J. Geophys. Res. 108, 2073 (2003)

23. R. Rapine, F. Tilmann, M. West, J. Ni, A. Rodgers, J. Geophys. Res. 108, 2120 (2003).

24. H. F. Sherrington, G. Zandt, A. Frederiksen, J. Geophys. Res. 109, B02312 (2004).

25. N.M. Shapiro, V. Levin. M.H. Ritzwoller, P. Molnar, D. Smith, Eos 84 (no. 46) (suppl.), F985 (abstr. S11C-0307) (2003).

26. T. Weiss, S. Siegesmund, W. Rabbel, T. Bohlen, M. Pohl, Pure Appl. Geophys. 156, 97 (1999).

27. O. Nishizawa, T. Yoshitno, Geophys. J. Int. 145, 19 (2001)

28. A. Meltzer, N. Christensen, Geophys. Res. Lett. 28 2129 (2001).

29. K. S. Aleksandrov, T. V. Ryzhova, Izv. Akad. Nauk SSSR Ser. Geofiz. 12, 186 (1961).
30. M. Barazangi, J. Ni, Geology 10, 179 (1982).

31. P. Molnar, P. England, J. Martinod, Rev. Geophys. 31, 357 (1993).

32. We used the central moment tensor catalog available on the Harvard Web site: www.seismology.harvard. edu/CMTsearch.html.

33. Details of the computations are presented on Science Online.

34. K. D. Nelson et al., Science 274, 1684 (1996)

35. Y. Makovsky, S. L. Klemperer, J. Geophys. Res. 104, 10795 (1999).

36. S. Roecker, Eos 80 (no. 46) (suppl.), F1017 (abstr. T41C-14) (1999).

37. A. F. Sheehan et al. Eos 80 (no. 47) (suppl.), F994 (abstr. S61D-11) (2002)

38. Most of the data used in this work were obtained from the Incorporated Research Institution for Seismology
Data Management Center and the GEOSCOPE Data Center. We are also particularly grateful to J. Trampert at Utrecht University; M. Antolik, A. Dziewonski, and G. Ekström at Harvard University for providing phase speed measurements; A. Sheehan and F. Wu for providing the HIMNT data; A. Levshin and A. van Hunen for help in preparing the data set; and P. England and C. Jones for helpful discussions. This work was supported by NSF grant EAR-0337622.

Supporting Online Material

www.sciencemag.org/cgi/content/full/305/5681/233/ DC1

Materials and Methods

Figs. S1 to S3

24 March 2004; accepted 1 June 2004

\section{InSAR Observations of Low Slip Rates on the Major Faults of Western Tibet}

\author{
Tim J. Wright, ${ }^{1 *}$ Barry Parsons, ${ }^{1}$ Philip C. England, ${ }^{1}$ \\ Eric J. Fielding ${ }^{2}$
}

Two contrasting views of the active deformation of Asia dominate the debate about how continents deform: (i) The deformation is primarily localized on major faults separating crustal blocks or (ii) deformation is distributed throughout the continental lithosphere. In the first model, western Tibet is being extruded eastward between the major faults bounding the region. Surface displacement measurements across the western Tibetan plateau using satellite radar interferometry (InSAR) indicate that slip rates on the Karakoram and Altyn Tagh faults are lower than would be expected for the extrusion model and suggest a significant amount of internal deformation in Tibet.

Western Tibet lies between the Indian plate and the Tarim Basin (Fig. 1), an undeforming block whose motion relative to Eurasia is mainly taken up by deformation in the Tien Shan range to the north (1). The two major strike-slip faults of the region are the Karakoram Fault, running NW-SE in the southern part of the plateau; and the western end of the Altyn Tagh Fault system, which runs approximately E-W at the northern end of the region. Models that regard India's motion relative to Tarim as being taken up principally by eastward extrusion on these strike-slip faults postulate about $30 \mathrm{~mm} /$ year of dextral (right-lateral) slip on the Karakoram Fault, and $20 \mathrm{~mm} /$ year of sinistral (left-lateral) slip on the western Altyn Tagh (2-5). In contrast, models that consider the continental lithosphere to resemble continuous media, with faults representing the near-surface localization of distributed deformation at depth (6-

${ }^{1}$ COMET, Department of Earth Sciences, University of Oxford, Oxford, UK. 2Jet Propulsion Laboratory, California Institute of Technology, Pasadena, CA 91109, USA, and Department of Earth Sciences, University of Cambridge, UK.

*To whom correspondence should be addressed. Email: tim.wright@earth.ox.ac.uk
$8)$, predict eastward extrusion of Tibet at no more than about $10 \mathrm{~mm} /$ year $(8-10)$

Previous measures of the rate of slip on these major fault systems have come from the offsets of geologic features, divided by the estimated ages of those features, and from geodetic measurements of recent (less than 10 years) ground displacement on lines crossing the faults. Offsets of up to $\sim 1000 \mathrm{~km}$ have been reported for geologic markers along the Karakoram Fault (3); division of such offsets by the presumed 30-million-year age of the motion yields a rate of $\sim 30 \mathrm{~mm} /$ year, consistent with the rate of $32 \pm 8$ $\mathrm{mm} /$ year calculated by dividing the observed
Table 1. Interferograms (ifm's) used in this study. the plateau. offsets of glacial moraine deposits by a presumed age of $\sim 10,000$ years (11). However, lower rates of 4 to $8 \mathrm{~mm} /$ year, based on geologic observations, have also been proposed for the Karakoram Fault $(12,13)$. These lower rates agree with geodetic measurements made over the past 10 years, which suggest rates of $3 \pm 5 \mathrm{~mm} /$ year (14) and $11 \pm 4 \mathrm{~mm} /$ year $(15)$.

On the Altyn Tagh Fault system, geologic estimates of slip rates are generally about 30 $\mathrm{mm} /$ year along the main portion of the Altyn Tagh Fault, with a somewhat lower rate $(\sim 20$ $\mathrm{mm} /$ year) at the western end (16). In contrast, geodetic measurements yield estimates of the rate of slip on the Altyn Tagh Fault system of $\sim 10 \mathrm{~mm} /$ year in its main portion $(1,17,18)$ and $7 \pm 3 \mathrm{~mm} /$ year in its western portion (1).

Attempts to explain the discrepancies between different studies include the suggestions that the ages assumed for offset glacial features may be underestimated by a factor of 3 or more $(12,19)$ and that field-based measurements, whether geologic or geodetic, may underestimate the total displacement across strike-slip zones. Satellite radar interferometry (InSAR) can circumvent these difficulties by producing maps of crustal deformation, with a spatial resolution of a few tens of meters and a precision of a few millimeters, that cover regions hundreds of kilometers in extent. Although measuring interseismic deformation is difficult using InSAR because of the small deformation signal, a few studies have shown that it is possible, provided that

\begin{tabular}{lccccc}
\hline & Image 1* & Image 2 & $\begin{array}{c}\text { Time } \\
\text { interval }\end{array}$ & $B_{\perp}(\mathrm{m}) \dagger$ & $\begin{array}{c}\sigma \\
\text { (mm/year) } \dagger\end{array}$ \\
\hline ifm1 & 13 November 1992 (ERS-1) & 24 June 1996 (ERS-2) & 3.6 years & -30 to 26 & 1.7 \\
ifm2 & 11 June 1993 (ERS-1) & 7 October 1996 (ERS-2) & 3.3 years & -17 to -90 & 1.2 \\
ifm3 & 3 December 1993 (ERS-1) & 22 October 1995 (ERS-1) & 1.9 years & -31 to 77 & 1.8 \\
ifm4 & 15 April 1996 (ERS-1) & 4 April 1999 (ERS-1) & 3.0 years & 24 to 10 & 1.4 \\
ifm5 & 19 May 1996 (ERS-1) & 5 April 1999 (ERS-2) & 2.9 years & 68 to 91 & 2.0
\end{tabular}

*SAR data (from the European Space Agency) are from standard descending track 291, frames 2871 to 2943 . Individual interferograms are shown in fig. S1. $\quad \dagger B_{\perp}$ is the perpendicular baseline separation of the satellite orbits at the scene center and varies along the track between the values shown. $\$$ Standard deviation of the interferogram noise on 